\title{
Ataxia Telangiectasia triggers deficits in Reelin pathway
}

\author{
Júlia Canet-Pons ${ }^{1}$, Ralf Schubert ${ }^{2 \#}$, Ruth Pia Duecker ${ }^{2}$, Roland Schrewe $^{2}$, Sandra Wölke $^{2}$, \\ Martina Schnölzer ${ }^{3}$, Georg Auburger ${ }^{1}$, Stefan Zielen $^{2 \ddagger}$, Uwe Warnken $^{3 \ddagger}$
}

${ }^{1}$ Exp. Neurology, ${ }^{2}$ Division for Allergy, Pneumology and Cystic Fibrosis, Department for Children and Adolescence, Goethe University Medical School, 60590 Frankfurt am Main,

${ }^{3}$ Functional Proteome Analysis, German Cancer Research Center (DKFZ), 69120 Heidelberg, Germany

\# Correspondence to Ralf Schubert: Ralf.Schubert@kgu.de

‡ These authors contributed equally to the work 


\section{Abstract}

Autosomal recessive Ataxia Telangiectasia (A-T) is characterized by radiosensitivity, immunodeficiency and cerebellar neurodegeneration. A-T is caused by inactivating mutations in the Ataxia-Telangiectasia-Mutated (ATM) gene, a serine-threonine protein kinase involved in DNA-damage response and excitatory neurotransmission. The selective vulnerability of cerebellar Purkinje neurons (PN) to A-T is not well understood.

Employing global proteomic profiling of cerebrospinal fluid from patients at ages around 15 years we detected reduced Calbindin, Reelin, Cerebellin-1, Cerebellin-3, Protocadherin Fat 2, Sempahorin 7A and increased Apolipoprotein $-\mathrm{B},-\mathrm{H},-\mathrm{J}$ peptides. Bioinformatic enrichment was observed for pathways of chemical response, locomotion, calcium binding and complement immunity. This seemed important, since secretion of Reelin from glutamatergic afferent axons is crucial for $\mathrm{PN}$ radial migration and spine homeostasis. Reelin expression is downregulated by irradiation and its deficiency is a known cause of ataxia. Validation efforts in 2-month-old Atm-/- mice before onset of motor deficits confirmed transcript reductions for Reelin receptors Apoer2/VIdlr with increases for their ligands Apoe/Apoh and cholesterol 24-hydroxylase Cyp46a1. Concomitant dysregulations were found for Vglut2/Sema7a as climbing fiber markers, glutamate receptors like Grin2b and calcium homeostasis factors (Atp2b2, Calb1, Itpr1), while factors involved in DNA damage, oxidative stress, neuroinflammation and cell adhesion were normal at this stage.

These findings show that deficient levels of Reelin signaling factors reflect the neurodegeneration in A-T in a sensitive and specific way. As an extracellular factor, Reelin may be accessible for neuroprotective interventions. 


\section{Keywords:}

Ataxia Telangiectasia, label-free mass spectrometry, diagnostic biomarkers, Reelin

\section{Introduction}

Ataxia-telangiectasia (A-T) is an autosomal recessive disorder defined clinicopathologically by degeneration of cerebellar Purkinje neurons (PN) combined with a dilatation of oculocutaneous small blood vessels. The patients suffer from immunodeficiency and radiosensitivity, which predisposes them to cancer [1]. A specific diagnostic biomarker in the extracellular compartment, the elevation of alpha-fetoprotein in blood serum is usually detected early in the disease progression [2,3]. The pathology is caused by mutations in the ATM (Ataxia-Telangiectasia Mutated) protein [4], a serinethreonine kinase that mainly participates in the DNA double-strand break response [5-8].

Unfortunately, none of its phosphorylation targets are among the critical factors of cerebellar ataxia pathways, so it remains to be understood how the vulnerability to DNA damage connects with the preferential neurodegeneration of Purkinje cells. Oxidative stress has been proposed as crucial, in view of several observations in patients and mouse models [9]. In A-T patient blood, elevated oxidative damage to lipids and DNA as well as altered glutathione levels were observed, suggesting adaptive mechanisms to oxidative stress [10,11]. A-T blood lymphocytes and skin fibroblasts show enhanced vulnerability to oxidative stress $[12,13]$. However, exposure of patient blood cell cultures to ionizing radiation or bleomycin showed significant differences in chromosomal breaks, 
while no elevation of oxidative stress markers TBARS, CAT, SOD was detected [14]. A re-analysis of this question in model organisms upon the first description of Atm-/- mice has emphasized that affected organs are targets of ROS-mediated damage, in particular the cerebellar PN [15]. The prominent role of oxidative stress for the deficient survival and dendritogenesis of PN was independently confirmed in Atm-/- mice [16]. Accumulation of DNA damage, alterations of the redox status and deficient calciumdependent excitability in the brains of Atm-/- mice could be demonstrated [17-19]. However, these investigations are hampered by the early death of Atm-/- mice by the age of 4-6 months due to thymic lymphomas, at a stage when their cerebellum appears histologically normal and the mice have no relevant movement deficit [20]. Only when their survival is extended to ages around 8 months by bone-marrow transplantation, a significant cerebellar atrophy with reduced numbers of PN becomes apparent by magnetic resonance imaging and calbindin-immunohistochemistry [21].

To identify further molecular biomarkers of risk and progression in A-T in the extracellular fluid, we studied cerebrospinal fluid (CSF) from patients by global proteome profiling with label-free mass-spectrometry (MS). Several pathway dysregulations were observed, which reflect deficient Reelin signals as completely novel finding, and altered calcium homeostasis, cellular motility and adhesion, as well as neuroinflammation. The crucial effects were validated at transcript level in the Atm-/- cerebellar tissue at very young age to assess their robustness and sensitivity. Importantly, we confirm very early and prominent deficits in Reelin signaling, which is secreted from cerebellar glutamatergic afferent fibers to control $\mathrm{PN}$ radial migration and dendritic differentiation. 


\section{Materials and methods}

\section{Patients}

Cerebrospinal fluid (CSF) was collected from 12 patients with A-T (7 male and 5 female) with an age distribution from 2.6 to 16.2 years (mean 10 years) and 12 control individuals ( 8 male and 4 female) that were age matched ( 0.2 to 19.6 , mean 8.6 years) (Table 1). The A-T patients were diagnosed on the basis of clinical criteria and AFP values, according to recent World Health Organization (WHO) recommendations [22]. The control group consisted of non-A-T patients receiving lumbar puncture due to another clinical indication. The SARA score [23] was used in patients as a quantitative measurement of the cerebellar ataxia.

Written consent from patients or caregivers was obtained from each subject. The study was conducted following the ethical principles of the Declaration of Helsinki, regulatory requirements and the code of Good Clinical Practice. The study was approved by the responsible ethics committees (application number 296/09) in Frankfurt and registered at clinicaltrials.gov NCT02285348.

Proteomic analysis of the CSF derived from the three oldest patients (14 years, 3 months; 14 years, 11 months and 16 years, 2 months; 2 male and 1 female) and the three oldest controls (14 years; 15 years, 7 months and 16 years, 9 months; 2 male and 1 female) were selected for further CSF analyses, which was performed by a label-free protein quantification approach using nano ultra-high performance liquid chromatography/ nano electrospray mass spectrometry (nano UPLC/ nanoESI-MS). Analysis of the data was performed with the MaxQuant quantitative proteomics software. 


\section{Sample preparation, gel electrophoresis and tryptic digestion}

Protein amounts ranging from 17 to $27 \mu \mathrm{g}$ (see below) were precipitated according to established protocols [24]. The obtained pellets were incubated with $30 \mu \mathrm{l}$ of LDS-buffer containing reducing agent (Invitrogen, Carlsbad, USA) for $10 \mathrm{~min}$ at $70^{\circ} \mathrm{C}$.

Subsequently, proteins were separated by 1D gel electrophoresis on a NuPAGE 4-12\% Bis-Tris gradient gel (Invitrogen, Carlsbad, USA) using a MOPS-buffer system. The gel was stained with colloidal Coomassie Blue for $3 \mathrm{~h}$. Afterwards each lane was cut into 27 pieces. Each individual gel piece was washed once with $100 \mu \mathrm{l} \mathrm{H}_{2} \mathrm{O}$ and $100 \mu \mathrm{l}$ $\mathrm{H}_{2} \mathrm{O} /$ acetonitrile $50 / 50(\mathrm{v} / \mathrm{v})$ and incubated for $5 \mathrm{~min}$ at $37^{\circ} \mathrm{C}$. After removing the solution from the gel plugs proteins were alkylated with $100 \mu \mathrm{l} 55 \mathrm{mM}$ iodoacetamide in $40 \mathrm{mM}$ $\mathrm{NH}_{4} \mathrm{HCO}_{3}$ for 30 min at $25^{\circ} \mathrm{C}$ in the dark, followed by three alternating washing steps each with $150 \mu \mathrm{l}$ of water and $\mathrm{H}_{2} \mathrm{O} /$ acetonitrile $50 / 50(\mathrm{v} / \mathrm{v})$ for 10 min at $37^{\circ} \mathrm{C}$. Gel pieces were dehydrated with $100 \mu \mathrm{l}$ neat acetonitrile for $1 \mathrm{~min}$ at room temperature, dried for 15 min and subsequently rehydrated with porcine trypsin (sequencing grade, Promega, Mannheim, Germany) with a minimal volume sufficient to cover the gel pieces after rehydration (100 ng trypsin in $40 \mathrm{mM} \mathrm{NH}_{4} \mathrm{HCO}_{3}$ ). After overnight digestion the supernatant was collected in PCR tubes, while gel pieces were subjected to four further extraction steps (acetonitrile/0.1\% TFA 50/50 (v/v)). The combined solutions were evaporated to dryness in a speed-vac concentrator and redissolved in $0.1 \%$ TFA/2.5\% hexafluoroisopropanol and subsequently analyzed by nanoLC-ESI-MS/MS. 


\section{NanoLC ESI-MS/MS analysis}

Tryptic peptides mixtures were separated using a nano Acquity UPLC system (Waters GmbH, Eschborn, Germany). Peptides were trapped on a nano Acquity C18 column, $180 \mu \mathrm{m} \times 20 \mathrm{~mm}$, particle size $5 \mu \mathrm{m}$ (Waters $\mathrm{GmbH}$, Eschborn, Germany). The liquid chromatography separation was performed on a C18 column (BEH $130 \mathrm{C} 18100 \mu \mathrm{m}$ x $100 \mathrm{~mm}$, particle size $1.7 \mu \mathrm{m}$ (Waters $\mathrm{GmbH}$, Eschborn, Germany) with a flow rate of $400 \mathrm{nl} / \mathrm{min}$. Chromatography was carried out using a $1 \mathrm{~h}$ gradient of solvent A $(98.9 \%$ water, $1 \%$ acetonitrile, $0.1 \%$ formic acid) and solvent B $(99.9 \%$ acetonitrile and $0.1 \% \mu \mathrm{l}$ formic acid) in the following sequence: from 0 to $4 \% \mathrm{~B}$ in $1 \mathrm{~min}$, from 4 to $40 \% \mathrm{~B}$ in 40 min, from 40 to $60 \% \mathrm{~B}$ in $5 \mathrm{~min}$, from 60 to $85 \% \mathrm{~B}$ in $0.1 \mathrm{~min}, 6 \mathrm{~min}$ at $85 \% \mathrm{~B}$, from 85 to $0 \% \mathrm{~B}$ in $0.1 \mathrm{~min}$, and $9 \mathrm{~min}$ at $0 \% \mathrm{~B}$. The nanoUPLC system was coupled online to an LTQ Orbitrap XL mass spectrometer (Thermo Scientific, Bremen, Germany). The mass spectrometer was operated in the data-dependent mode to automatically measure MS1 and MS2. Following parameters were set: ESI voltage $2400 \mathrm{~V}$; capillary temperature $200^{\circ} \mathrm{C}$, normalized collision energy $35 \mathrm{~V}$. Data were acquired by scan cycles of one FTMS scan with a resolution of 60000 at $\mathrm{m} / \mathrm{z} 400$ and a range from 300 to $2000 \mathrm{~m} / \mathrm{z}$ in parallel with six MS/MS scans in the ion trap of the most abundant precursor ions.

\section{MaxQuant}

Protein quantification was performed with the MaxQuant software 1.5.3.8 [25] wherein peptide identification was performed using the Andromeda [26] search engine integrated into the MaxQuant environment against the human SwissProt database (uniprotorganism_9606+reviewed_yes 03/2016, 20274 sequences). The peptide mass tolerance 
for database searches was set to $7 \mathrm{ppm}$ and fragment mass tolerance to $0.4 \mathrm{Da}$. Cysteine carbamidomethylation was set as fixed modification. Variable modifications included oxidation of methionine, deamidation of asparagine and glutamine, as well as protein $\mathrm{N}$-terminal acetylation. Two missed cleavage sites in case of incomplete trypsin hydrolysis were allowed. Furthermore, proteins were considered as identified if at least two unique peptides were identified. Identification under the applied search parameters refers to false discovery rate $(F D R)<1 \%$ and a match probability of $p<0.01$, where $p$ is the probability that the observed match is a random event. Data transformation and evaluation was performed with the Perseus software (version 1.5.2.4) [27]. Contaminants as well as proteins identified by site modification only and proteins derived from decoy database containing reversed protein sequences were strictly excluded from further analysis. Protein ratios were calculated by label free quantification (LFQ) comparing experiment and control samples. Filtering for quantitative values was applied to have at least two valid LFQ values in three replicates of either the experiment or the control group. To avoid zero LFQ values for calculating protein expression levels, values equal zero were substituted by values calculated from normal distribution of each data set regarded. For statistical analyses, 2-sample t-tests were performed to calculate differences in the protein abundance between these groups ( $p$-value $<0.05$ ). Proteins were only considered as significantly regulated and ranked as potential PPI complex partners if their abundance changed more than +2 -fold.

\section{Bioinformatic pathway enrichment analyses}


For protein-protein interaction (PPI) network analysis, the software tool String v.10 (https://string-db.org/) with standard settings has been employed to visualize networks of significant dysregulations [28]. As recommended, gene symbols of factors with significant dysregulation were entered into the Multiple Proteins window, so that the graphic interaction diagram was generated and archived. Automated network statistics were done; significant functional enrichments of GO (Gene Ontology) terms and KEGG pathways were exported into EXCEL files.

\section{Animal breeding and brain dissection}

Atm-/- $\left(A t m^{\mathrm{tm} 1 \mathrm{Awb}}\right)$ mice were used as the model of A-T [15], together with age- and sexmatched wildtype (WT) animals in the 129SvEv genetic background strain. All procedures were performed according to protocols approved by the German Animal Subjects Committee (Gen.Nr.FK/1006). Mice were housed in accordance with the German Animal Welfare Act, Council Directive of 24 November 1986 (86/609/EWG) Annex II, ETS123, and the EU Directive 2010/63/EU for animal experiments at the FELASA-certified Central Animal Facility (ZFE) of the Frankfurt University Medical School. The mice were housed in Type II L cages $\left(365 \times 207 \times 140 \mathrm{~mm}^{3}\right.$, floor area $530 \mathrm{~cm}^{2}$ ), with mutants and controls being bred and aged in parallel under controlled conditions of temperature, humidity, and light/ dark cycles of $12 \mathrm{~h}$. Food and water were accessible ad libitum. Genotyping was performed on extracted tail DNA using PCR techniques were described previously [29]. Following cervical dislocation, fresh cerebellar tissue from 8 Atm-/- versus 8 WT animals with an age of 1-3 months was dissected and snap-frozen in liquid nitrogen for expression analyses. 


\section{Expression study at transcript level in a mouse model of A-T}

Total RNA from frozen cerebellum was isolated using TRIzol reagent (Sigma-Aldrich), following the instructions of the manufacturer. The RNA quality and quantity were measured with a BioPhotometer (Eppendorf) at $260 \mathrm{~nm}$. DNase treatment of $1 \mu \mathrm{g}$ RNA was performed using DNase Amplification Grade (Invitrogen). Reverse transcription was carried out with SuperScript IV VILO Master Mix (Invitrogen) as recommended. Gene expression assays were performed from $20 \mathrm{ng}$ of cDNA in 96-well optical plates with a StepOnePlus Real-Time PCR system. Replicates from each sample were included per assay. The reaction mix consisted of $5 \mu \mathrm{l}$ cDNA, $1 \mu \mathrm{l} 20 \mathrm{x}$ TaqMan gene expression assay, $10 \mu \mathrm{l}$ of 2x FastStart Universal Probe Master (ROX; Roche) and $4 \mu \mathrm{l}$ Gibson DNAse/RNAse free water. The following TaqMan assays were used for reversetranscriptase quantitative polymerase chain reaction (qPCR) in the mouse tissue: $A b c a 1$ - Mm00442646_m1; Apob - Mm01545150_m1; Apod - Mm01342307_m1; Apoe Mm00437573_m1; Apoer2 - Mm00474030_m1; Apoh-Mm00496516_m1; Apoj (Clu) Mm00442773_m1; Atp2a2 - Mm01201431_m1; Atp2b2 - Mm00437640_m1; Atr Mm01223626_m1; Calb1 - Mm004886647_m1; Calm1 - Mm01336281_g1; Cbln1 Mm01247194_g1; Cbln3 - Mm00490772_g1; Cntn2 - Mm00516138_m1; Cyp46a1 Mm00487306_m1; Dab1 - Mm00438366_m1; Dab2 - Mm01307290_m1; Efemp1 Mm01295779_m1; Fan1 - Mm00625959_m1; Fat2 - Mm01295779_m1; Fgfr1 Mm00438930_m1; Gria1 - Mm00433753_m1; Gria2 - Mm00442822_m1; Gria3 Mm00497506_m1; Gria4 - Mm00444754_m1; Grin1 - Mm00433800_m1; Grin2a Mm00433802_m1; Grin2b - Mm00433820_m1; Grin2c - Mm00439180_m1; Grin2d - 
Mm00433822_m1; Grin3a - Mm01341722_m1; Grin3b - Mm00504568_m1; Grm1 Mm00810219_m1; Grm3 - Mm00725298_m1; Grm4 - Mm01306128_m1; Grm5 Mm00690332_m1; Grm7 - Mm01189424_m1; Grm8 - Mm00433840_m1; Gsk3b Mm00444911_m1; Gsr - Mm00439154_m1; Gss - Mm00515065_m1; Gstp1 Mm04213618_gH; Hmgcs1 - Mm01304569_m1; Homer3 - Mm00803747_m1; Ighm Mm01718955_g1; Inpp5a - Mm00805812_m1; Itih2 - Mm01337594_m1; Itih4 Mm00497648_m1; Itpka - Mm00525139_m1; Itpr1 - Mm00439907_m1; Jup Mm00550256_m1; KitL - Mm00442972_m1; Ldlr - Mm01177349_m1; Lrp1 Mm00464608_m1; Lrp6 - Mm00999795_m1; MIh1 - Mm00503449_m1; Pafah1b1 Mm00443070_m1; Pafah1b2 - Mm00476594_m1; Pafah1b3 - Mm00476597_m1; Pms2 - Mm01200871_m1; Reln - Mm00465200_m1; Rrm2b - Mm01165706_m1; Scg2 Mm04207690_m1; Sema7a - Mm00441361_m1; Sod1 - Mm01344233_g1; Sparc Mm00486332_m1; Trpc3 - Mm00444690_m1; Tst - Mm01195231_m1; Txnb Mm00466624_m1; Vglut1 - Mm00812886_m1; Vglut2 (Slc17a6) - Mm00499876-m1; VIdlr - Mm00443298_m1. Transcript levels of Tbp (Mm00446973_m1) were employed as internal loading control for normalization. Expression levels were analyzed with the $2^{-}$ $\Delta \Delta \mathrm{Ct}$ method [30]. 


\section{Results and Discussion}

\section{A-T patient CSF shows progressive elevation of protein and albumin}

To identify diagnostic markers and to elucidate the molecular events for the neurodegeneration in A-T, we analyzed the CSF from 12 patients and 12 sex- and agematched control individuals. In addition to diagnostic tests such as neuroimaging (Fig. 1A), clinical ataxia scores and determination of alpha-fetoprotein levels were documented (summary of basal characteristics in Table 1). In good correlation with the progressive increase of ataxia scores during the ageing process (Fig. 1B), also the CSF total protein and albumin levels increased significantly in patients, but not in controls (Fig. 1C-D). Among patients aged 10 to 16 years, total protein and albumin levels showed better correlation to age than the ataxia scores.

\section{Global proteomics reveals several dysregulations in the Reelin signaling pathway}

The three oldest patients (ages 14-16 years) with strongest increase of total protein and albumin were selected for further CSF analyses by MS, together with the three oldest controls. The global proteome bioinformatics identified similar numbers of CSF proteins in patient and controls (Table 1). In comparison to previously reported data [31], we identified 820 proteins in the CSF samples of our group of patients, among which 66 proteins were found with significant differences in protein expression, including downregulations for 44 proteins and upregulations for 22 proteins (Table 2). Our data confirm all the 13 priority proteins reported previously in the CSF of A-T patients [31], but 
only Secretogranin and SPARC dysregulations reached significance in CSF of our patients.

The visualization of our data in volcano plots (Fig. 2), where fold changes are plotted on the $\mathrm{X}$-axis and significance is plotted on the $\mathrm{Y}$-axis, revealed the prominent PN vulnerability by a particularly strong reduction of Calbindin $\left(\log _{2}\right.$ fold change of -2.75 representing a decrease to $15 \%$ ), as expected for this abundant calcium-homeostasis factor that is specific for the GABA-ergic PN and is usually deficient in cerebellar ataxias [32].

As completely novel finding, a similarly strong downregulation was observed for Reelin (RELN, to $15 \%$ ), which is expressed by the glutamatergic granule neurons of cerebellum [33]. The deficiency of Reelin could be upstream from PN degeneration in A-T, in view of previous knowledge: A spontaneous Reelin deletion in mouse (the famous "reeler" mutant strain) causes ataxia due to brain cortex foliation defects from migration anomalies along radial glia, prominently affecting cerebellar $\mathrm{PN}[34,35]$. In man, a rare autosomal recessive ataxia due to cerebellar hypoplasia with lissencephalopathy is caused by Reelin deficiency [36]. Reelin is a large secreted extracellular matrix glycoprotein that activates apolipoprotein receptors. The interaction between two APOE receptors (VLDLR and APOER2) and Reelin, as one of their ligands, controls not only neuronal positioning during brain development, but also synaptic plasticity in the adult brain $[37,38]$. APOE is a cholesterol transport protein and Reelin modulates intracellular cholesterol efflux in macrophages [39]. Reelin also influences postsynapses in their glutamatergic NMDA receptor composition, modulating postnatal neurogenesis, enhancing spine hypertrophy and long-term potentiation [40]. 
Reelin is very credible to be involved in ATM-triggered pathogenesis, for several reasons. Cerebellar Reelin is downregulated upon X-irradiation stress of embryos in the late gestation stage or upon corticosteroid exposure $[41,42]$. Reelin is expressed in glutamatergic granule neurons of the cerebellum, which secrete it from parallel fiber presynapses to PN dendrites and ensure spine development $[33,43,44]$. During adult life, Reelin is involved in the degeneration of PN [45]. Reelin signals are detected by the VLDLR and ApoER2 receptors, before they are intracellularly transduced in phosphorylation-dependent manner by DAB1 and the LIS1/PAFAH1B complex [46-48]. A mutation in PAFAH1B3 was reported to trigger ataxia and brain atrophy [49].

In excellent agreement with the observation of Reelin dysregulation, a significant downregulation was detected also for Fibroblast Growth Factor Receptor 1 (FGFR1, to $38 \%$ ), which is expressed in the radial glia of cerebellum [50]. This trophic signaling molecule was already implicated in ATM-dependent genotoxicity response and in Reelin-dependent radial glia migration, with secondary effects on granule neurons and PN in the cerebellum [51-53]. The upregulation of Notch-3 (NOTCH3, to $260 \%)$ may be related to the same pathway, since NOTCH3 has been implicated in the role of Bergmann astroglia for the radial migration of neurons during cerebellar corticogenesis [54].

Further support for the central role of Reelin signaling in this proteome profile came from the massive upregulation observed for Apolipoprotein B-100 (APOB, to 1282\%). This lipid transporter shows preferential expression in granule neurons and PN of the cerebellum according to the Allen mouse brain atlas (http://mouse.brainmap.org/gene/show/88416). The APOB/LDLR interaction activates the PI3K-PKC $3-S p 1-$ 
ABCA1 pathway in parallel manner to the Reelin/APOE-VLDLR/APOER2-DAB1 cascade in the control of cholesterol homeostasis [55]. The levels of APOB and the Reelin receptor VLDLR are known to correlate inversely [56]. Also the upregulation of Junction Plakoglobin (JUP, to $217 \%$ ) is relevant here, since this adhesion factor interacts with DAB2 [57].

Finally, the significant upregulation of Apolipoprotein $\mathrm{J}$ (also called Clusterin, CLU, to $159 \%$ ) in A-T patient CSF is relevant. Although the main isoform is a Golgi-localized molecular chaperone, a secreted isoform acts as ligand for the VLDLR and APOER2 receptor to signal via the Reelin pathway [58-60]. Furthermore, Apolipoprotein $\mathrm{J}$ is a known marker of PN pathology $[61,62]$, its genetic variants play a role for hereditary dementia similar to variants in NOTCH3 [63], and its plasma concentration is associated with brain atrophy [64]. Moreover, the upregulations of APOB and CLU were accompanied by increased levels of Apolipoprotein $\mathrm{H}(\mathrm{APOH}$, to $157 \%)$ as a mediator of inflammatory changes [65], and of Serum Amyloid P Component (APCS, to 248\%) as a suppressor of immune responses to abnormal DNA, known to genetically interact with APOE $[66,67]$. A relevant upregulation was also detected for Paraoxonase 1 (PON1, to $228 \%$ ), which serves as universal factor of antioxidant defense [68]. PON1 detoxifies oxidized low density lipoprotein (LDL) [69], is secreted from cells with VLDL [70], is inhibited in activity by VLDL-associated triglycerides [71] and is associated with familial combined hyperlipidemia [72].

Thus, there is a clear enrichment of Reelin signaling and apolipoprotein homeostasis factors among the A-T CSF dysregulations. 


\section{Protein interaction bioinformatics suggest glutamatergic axon input to PN as site of pathology, while identifying molecular biomarkers of neuroinflammation}

In order to complement this literature-driven prioritization by additional unbiased bioinformatics, all significantly dysregulated proteins in Table 2 were screened for enrichments of specific biological processes, molecular functions, KEGG pathways and protein domains at the STRING webserver of the European Molecular Biology Laboratory in Heidelberg (Fig. 3). As assumed, significant protein-protein-interaction enrichment was observed for both the downregulations $(p=0.00948)$ and upregulations $(p=1.11 \mathrm{e}-15)$. Among the cellular components, enrichments for the extracellular region were detected for 36 downregulated (false discovery rate $q=4.86 e-16$ ) and 20 upregulated proteins $(q=2.11 \mathrm{e}-09)$, as expected for a study in CSF.

Among the 44 downregulations (Fig. 3A), novel specific insights included a significant enrichment for 18 factors in the "response to chemical" ( $q=0.04$, illustrated as light green bullets), among which RELN and SPARC (Secreted Protein Acidic and Cysteine Rich, to $49 \%$ ) are involved in the response to irradiation [73,41], while CNTN2 (Contactin-2, to $78 \%$ ) is involved in granule neuron radial migration [74,75]. A significant enrichment was observed also for 10 factors in the "regulation of locomotion" ( $q=0.00962$, illustrated as red bullets in Fig. 4A), among which SERPINE2 (Serpin Family-E Member-2, to 34\%) regulates the differentiation of cerebellar granule neurons, while PLXNB2 (Plexin-B2, to $62 \%)$ is involved in their migration [76,77]. Significant enrichment was found as well for 13 factors in "calcium ion binding" ( $q=2.38 \mathrm{e}-06$, illustrated as purple bullets), among which the massive decrease of the protocadherin adhesion factor FAT2 (FAT Atypical Cadherin-2, to $3 \%$ ) deserves special interest, since FAT2 is localized at parallel fibers of 
cerebellar granule neurons, is driving cellular motility, and its mutation causes Spinocerebellar ataxia type 45 [78-80]. Finally, a significant enrichment was observed for 3 factors with a "C1q domain" ( $q=0.009$, illustrated as yellow bullets), among which the downregulations of CBLN1 (Cerebellin-1, 19\%) and CBLN3 (Cerebellin-3, 4\%) were particularly strong. Both are secreted from parallel fibers of granule neurons and colocalize as heterodimeric complex with the glutamatergic GluRdelta2 receptor [81]. CBLN1 deficiency in mice was reported to cause cerebellar ataxia [82]. Further downregulations of relevance were detected for the motility factor ENPP2 (Ectonucleotide Pyrophosphate / Phosphodiesterase-2, to 48\%) [83], the PN marker SEMA7A (Semaphorin-7A, to 39\%) [84], and the PN-expressed adhesion factor CNTN6 (Contactin-6, to 15\%) that acts as NOTCH1 ligand $[85,86]$. CNTN6 deficiency in mice triggers ataxia [87]. In summary, markers for the glutamatergic parallel fiber afferents to PN, which originate in cerebellar granule neurons (such as FAT2 to 3\%, CBLN3 to 4\%, RELN to $15 \%$, CBLN1 to $19 \%$ ), appeared to be at least as diminished as PN markers (CALB1 to $15 \%$, CNTN6 to $15 \%$, SEMA7A to 39\%). Overall, key factors of PN connectivity with their glutamatergic input axons are prominent among the downregulations.

Among the 23 upregulations (Fig. 3B), novel specific insights included enrichments of 5 factors in the "humoral immune response" ( $q=0.00007$, illustrated as deep green bullets), among which CLU was already mentioned, while IGHM (Immuno-Globulin Heavy Constant Mu chain, to $2216 \%$ ) is involved in acute inflammatory stress responses. Although not recognized by the automated bioinformatics, the upregulated factor CHI3L2 (Chitinase-3 Like-2, to $384 \%$ ) is also involved in inflammatory responses [88,89], similar to the upregulated factors CPN2 (Carboxypeptidase-N Subunit-2, to 817\%) [90] and the 
cholesterol biosynthesis suppressor CD5L (CD 5 Molecule Like, to 773\%) [91-94].

Significant enrichment was found as well for 3 factors in the innate immunity “complement and coagulation cascades" ( $q=0.017$, illustrated as ochre bullets), among which C8G (Complement Component-8 Gamma Chain, to 195\%) is part of the secreted lipocalin gene family and was implicated in the interleukin-6-mediated induction of acutephase response $[95,96]$, while C4BPA (Complement Component-4 Binding Protein A, to $143 \%$ ) binds DNA to inhibit DNA-mediated complement activation and inflammatory responses against necrotic cells [97]. Significant enrichment was found also for 3 factors in the "hyaluronan metabolic process" ( $q=0.008$, illustrated as light blue bullets), namely ITIH1 (Inter-Alpha-Trypsin Inhibitor Heavy Chain-1, to 271\%), ITIH2 (Inter-Alpha-Trypsin Inhibitor Heavy Chain-2, to 236\%) and ITIH4 (Inter-Alpha-Trypsin Inhibitor Heavy Chain4 , to $213 \%$ ). While the brain role of this gene family has not been thoroughly investigated, ITIH4 is induced by interleukin-6 during the acute phase response to infection [98,99]. Overall, neuroinflammatory responses are prominent among the upregulations.

\section{Validation in Atm-/- cerebellar mRNA confirms early Reelin signaling deficit}

To assess whether these pathways have a prominent role also in cerebellar tissue of the A-T mouse model, we employed Atm-/- animals that were previously shown to die at ages of 4-6 months due to thymic lymphomas without showing signs of cerebellar degeneration. A hallmark of these mice is the high level of oxidative stress by Reactive Oxygen Species (ROS) that affects several tissues at the end of their lifespan, including the cerebellum [15]. Instead of quantifying secreted factors or studying their extracellular 
turnover, we analyzed transcript levels in 2-month-old cerebellar tissue for key components in several pathways, which were suggested by the A-T patient CSF proteomic profiles, namely cholesterol-apolipoprotein trafficking, Reelin signaling, glutamatergic input to PN, glutamate receptors, calcium homeostasis, oxidative stress, neuroinflammation and cell adhesion (Fig. 4).

As evidence for altered cholesterol trafficking and increased synthesis of ligands that may substitute for Reelin (Fig. 4A), significant increases were observed for the cholesterol-transporting apolipoproteins Apoe (to 127\%, p=0.033), Apoh (to 159\%, $\mathrm{p}=0.032$ ) and the cholesterol efflux regulator Cyp46a1 (to 135\%, $\mathrm{p}=0.020$ ), while markers for oxidative stress showed no dysregulation at this stage (Fig. 4B). As a crucial confirmation of the Reelin reduction in patient CSF, already these young Atm-/cerebella showed significant mRNA decreases for both receptors of Reelin, namely VIdlr (to $82 \%, p=0.037$ ) and Apoer2 (to $82 \%, p=0.0003$ ) upon qPCR (Fig. 4C). The transcriptional synthesis of the Reelin transcript (Reln) itself and its intracellular transducers Pafah1b1, Pafah1b2, Pafah1b3, Dab1, Dab2 and Gsk3b appeared normal (Fig. 4C).

Analyzing key factors for the interaction of PN with excitatory afferents (Fig. 4D) demonstrated increased levels of the Sema7a (to $123 \%, p=0.009$ ), a factor that is secreted from PN and contributes to the selective elimination of climbing fibers [84]. Indeed, a strong reduction was documented for Vglut2 (to $57 \%, p=0.013$ ), which serves as marker for climbing fibers and reflects the earliest pathology also in Spinocerebellar Ataxia type 1 [100]. There were no dysregulations for the Cerebellins $(C b / n 1 / C b / n 3)$ or Fgfr1 at this stage (Fig. 4D), nor for any marker of DNA-damage repair and 
neuroinflammation under analysis (Fig. 4E). Consistent with the concept of altered lipid signaling and glutamatergic afferents, the glutamate NMDA receptor subunit Grin2b mRNA showed a strong upregulation (to 156\%, $\mathrm{p}=0.034$ ) (Fig. 4F). Given that Reelin levels are known to modulate GRIN2B levels in a reverse correlation during postnatal life $[40,101]$, this Grin2b elevation supports the notion that Reelin signals are deficient in Atm-/- mouse cerebella already at the age of 2 months. In contrast, Grin2c was downregulated (to $91 \%, p=0.018$ ), while upregulations were observed for the AMPA receptor subunits Gria1 (to $115 \%, p=0.049$ ), Gria2 (to $110 \%, p=0.044$ ) and for the metabotropic receptor subunit Grm3 (to 121\%, p=0.045) (Fig. 4F).

Among the calcium homeostasis factors, the significant decreases of mRNAs encoding the PN marker Calbindin-1 (Calb1 to 79\%, $\mathrm{p}=0.011$ ), the Plasma Membrane Calcium ATPase (Atp2b2 to 85\%, $\mathrm{p}=0.024)$ and the ER-associated Inositol-1,4,5-TrisphosphateReceptor-1 (Itpr1 to 78\%, p=0.026) were reflecting the deficient excitability of PN, downstream from Reelin and Glutamate signals (Fig. 4G). In comparison, none of the cell adhesion markers that were assessed showed any significant dysregulation (Fig. 4H). Thus, the transcriptional analyses confirm Reelin signaling deficits before the advent of altered locomotor behavior and PN death. Our data also indicate that the pathways of lipid and glutamate signaling with downstream calcium-dependent excitability are affected before DNA damage repair, oxidative stress responses, neuroinflammation and cellular adhesion show detectable changes. A diagram (Fig. 5) illustrates the scenario within the 2-month-old Atm-/- cerebellar circuitry, with red letters highlighting upregulated factors, while blue letters denote downregulations. 


\section{Conclusion}

Comprehensive evaluations of pathogenesis pathways and of potential biomarkers have become possible via high-throughput sequencing technology. The advent of personalized medicine will make these approaches at DNA, RNA, protein and lipid level available soon in many hospitals to counsel families regarding disease risk, progression and therapy benefit. For A-T diagnostics, the levels of alpha-fetoprotein in blood extracellular fluid serve as well-established critical biomarker, so now for the first time the brain extracellular fluid was evaluated in a quantitative global screen. The CSF findings identified prominent changes of Reelin/apolipoprotein signaling and possibly adhesion at sites of glutamatergic input to $\mathrm{PN}$, accompanied by neuroinflammatory activation, with surprising consistency. Our study therefore provides proof-of-principle that this approach is useful and should be pursued in further patients and genetic model studies.

The molecular dysregulations observed may be part of the irradiation and DNA damage repair pathways, given that Reelin and SPARC are modulated during radioresistancereversal, while APCS and C4BPA interact with abnormal DNA. They may be part of neural migration and synaptic mobility, which certainly will involve extracellular factors that modulate adhesion, signal responses and locomotion. But importantly, the pathogenesis may also relate to altered glutamatergic excitation of PN dendrites. The ATM protein was recently shown to be a crucial facilitator of synaptic excitatory vesicle release, in a fine balance with the ATR protein that is responsible for inhibitory neurotransmission [102]. ATM levels rise in response to a blockade of NMDA receptors 
[102], so an influence on NMDA receptor composition and synaptic plasticity by Reelin signals $[40,103]$ may play a key role in ATM deficiency. Dysfunction of the glutamatergic parallel fiber input is known to result in PN death [104]. Indeed, our transcriptional analyses in 2-month-old Atm-/- cerebella support the concept that Reelin signaling deficits are a novel, early and important feature in the pathogenesis of A-T neurodegeneration. Furthermore, our data suggest that the changes in signaling and excitability occur before responses to DNA damage, oxidative stress, neuroinflammation or cell adhesion deficits become notable.

To establish new approaches of neuroprotective value, it is important to note that the addition of recombinant Reelin to organotypic slice cultures via conditioned medium was observed to rescue the pathology of synaptic vesicles and of paired-pulse facilitation in reeler mutant mice [105]. In addition, the expression of Reelin and VLDLR can be upregulated by administration of the psychotropic drug olanzapine [106]. Thus, our observations may hold therapeutic value. 


\section{Acknowledgements}

This research received funding from the A-T Children's Project. We thank Dr. Suzana

Gispert-Sánchez and Katrin Krug for advice and technical assistance. We are also

grateful to Konrad Bochennek for the collection of the CSF samples and give many

thanks to Ramona Mayer for sample preparation for mass spectrometry. 


\section{Table 1. Patients' Characteristics}

\begin{tabular}{lcc}
\hline Parameters & Controls $(n=12)$ & A-T patients $(n=12)$ \\
\hline Age [years] & $8.5 \pm 6.4$ & $10.0 \pm 4.8$ \\
Sex [Female/Male] & $4 / 8$ & $5 / 7$ \\
Height [cm] & $128 \pm 40.4$ & $128 \pm 26.3$ \\
Weight [Kg] & $32.0 \pm 23.7$ & $31.1 \pm 19.4$ \\
Ataxia Score & --- & $20.2 \pm 4.2$ \\
$\alpha$-Fetoprotein [ng/ml] & $<10.0$ & $334 \pm 215$ \\
& $887 \pm 133^{*}$ & $820 \pm 182^{*}$ \\
Identified CSF proteins in MS & &
\end{tabular}

Table 1. Basal diagnostic features of individuals studied. 
Protein Names

Gene Names

Minus LOG

(P-value)
Fold Change

(negative values

indicate down

regulations)
Carbonic anhydrase 2

Ig mu chain $\mathrm{C}$ region

C4b-binding protein alpha chain

Adenylate kinase isoenzyme 1

Apolipoprotein B-100;Apolipoprotein B-48

Carboxypeptidase $\mathrm{N}$ subunit 2

CD5 antigen-like

Eukaryostic translation initiation

Factor $5 \mathrm{~A}$ and Like1

Chitinase-3-like protein 2

Isocitrate dehydrogenase [NADP]

cytoplasmic

Inter-alpha-trypsin inhibitor heavy

chain $\mathrm{H} 1$

Neurogenic locus notch homolog protein 3

Serum amyloid P-component

Inter-alpha-trypsin inhibitor heavy chain $\mathrm{H} 2$

Serum paraoxonase/arylesterase 1

Junction plakoglobin

Inter-alpha-trypsin inhibitor heavy chain $\mathrm{H} 4$

Complement component $\mathrm{C} 6$

Complement component C8 gamma chain

Clusterin

Beta-2-glycoprotein 1

14-3-3 protein zeta/delta

Contactin-2

Fibulin-1

Gamma-glutamyl hydrolase

SPARC-like protein 1

Plexin-B2

$45 \mathrm{kDa}$ calcium-binding protein

Beta-mannosidase

Pro-cathepsin $\mathrm{H}$

EGF-containing fibulin-like extracellular matrix protein 1

Secreted Protein Acidic And Cysteine Rich

Ectonucleotide pyrophosphatase/

phosphodiesterase family member 2

$\mathrm{N}$-acetylglucosamine-1-phosphotransferase subunit gamma

$78 \mathrm{kDa}$ glucose-regulated protein
CA2

IGHM

C4BPA

AK1

APOB

CPN2

CD5L

EIF5A; EIF5AL1

CHI3L2

IDH1

ITIH1

NOTCH3

APCS

ITIH2

PON1

JUP

ITIH4

C6

C8G

CLU

$\mathrm{APOH}$

YWHAZ

CNTN2

FBLN1

GGH

SPARCL1

PLXNB2

SDF4

MANBA

$\mathrm{CTSH}$

EFEMP1

SPARC

ENPP2

GNPTG

HSPA5
1.46

1.44

2.93

2.17

2.36

1.46

2.19

1.60

1.43

1.68

1.92

1.46

3.47

1.78

1.41

2.01

2.39

1.71

1.30

1.60

1.40

1.31

1.74

2.19

2.00

1.60

1.35

2.31

1.45

1.63

2.44

3.02

1.32

1.50

1.67
6.03

4.47

3.84

3.73

3.68

3.03

2.95

2.66

1.94

1.69

1.44

1.38

1.31

1.24

1.19

1.12

1.09

0.99

0.96

0.67

0.65

0.59

$-0.36$

$-0.41$

$-0.66$

$-0.66$

$-0.69$

$-0.70$

$-0.79$

$-0.83$

$-1.02$

$-1.04$

$-1.06$

$-1.06$

$-1.06$ 
Protein Names
Minus LOG (P-value)
Fold Change

(negative values indicate down regulations)
Pyruvate kinase PKM

Di-N-acetylchitobiase

Collagen alpha-1(VI) chain

Lymphocyte antigen $6 \mathrm{H}$

Dihydropteridine reductase

Semaphorin-7A

Secretogranin-1

Fibroblast growth factor receptor 1

Cell surface glycoprotein MUC18

Glia-derived nexin

Carbonic anhydrase 4

Phosphoinositide-3-kinase-interacting protein 1

Probable serine carboxypeptidase CPVL

Carboxypeptidase Q

Phosphatidylcholine-sterol acyltransferase

Mammalian ependymin-related protein 1

Fibromodulin

Cerebellin-1

Kallikrein-11

Mannosyl-oligosaccharide 1.2-alphamannosidase IA

Reelin

Contactin-6

Plasma alpha-L-Fucosidase

Calbindin

Collectin-12

Nucleobindin-1

Testican-2

Complement $\mathrm{C} 1 \mathrm{q}$ tumor necrosis factorrelated protein 5

Cerebellin-3

Protocadherin Fat 2

Ig gamma-4 chain $\mathrm{C}$ region
Gene Names

PKM; PKM2

CTBS

COL6A1

LY6H

QDPR

SEMA7A

CHGB

FGFR1

MCAM

SERPINE2

CA4

PIK3IP1

CPVL

CPQ

LCAT

UCC1; EPDR1

FMOD

CBLN1

KLK11

MAN1A1

RELN

CNTN6

FUCA2

CALB1

COLEC12

NUCB1

SPOCK2

C1QTNF5

CBLN3

FAT2

IGHG4

\subsection{7}

1.85

2.87

1.42

1.66

1.31

2.69

2.21

1.68

1.58

1.50

1.37

1.43

2.80

1.37

2.17

2.16

2.25

2.68

2.41

2.21

1.58

2.33

2.24

1.58

2.69

1.99

4.40

1.99

1.47

1.51
$-1.15$

$-1.19$

$-1.20$

$-1.20$

$-1.32$

$-1.34$

$-1.34$

$-1.38$

$-1.39$

$-1.57$

$-1.71$

$-1.86$

$-1.89$

$-2.03$

$-2.33$

$-2.37$

$-2.38$

$-2.42$

$-2.42$

$-2.43$

$-2.69$

$-2.71$

$-2.75$

$-2.75$

$-2.98$

$-3.13$

$-3.85$

$-3.85$

$-4.65$

$-5.09$

$-5.14$

Table 2. Proteins differentially expressed in CSF in the three oldest patients with A-T vs. control individuals. 


\section{Legends}

Figure 1. Progressive neurodegeneration in A-T: (A) The shrinking cerebellum of an A-T patient is surrounded by excess amounts of CSF (highlighted by white arrows). This extracellular fluid generates high intensity values (shown as light grey or white) in this T2-weighted magnetic resonance image. (B) Age-associated progression of SARA ataxia scores is documented for 12 patients. (C) Total protein and (D) Albumin concentrations analyzed in CSF of the $12 \mathrm{~A}-\mathrm{T}$ patients and control individuals. Black symbols illustrate the 3 patients and 3 controls selected for CSF global proteome profiling.

Figure 2. Proteomic analysis of the Cerebro-Spinal Fluid (CSF) collected from 3 oldest patients and controls (age 14-16 years). Analysis of the CSF of A-T samples was performed by a label-free protein quantification approach using nano ultra-high performance liquid chromatography/ nano electrospray mass spectrometry (nano UPLC/ nanoESI-MS). (A) Analysis of the data was performed with the MaxQuant quantitative proteomics software and illustrated by a Volcano plot. The red squares indicate proteins that display both large-magnitude fold-changes ( $\mathrm{x}$-axis) as well as high statistical significance (-log of p-value, y-axis). Label-free quantitation is shown for (B) Reelin, (C) Calbindin, (D) Cerebellin-3 and (E) Cerebellin-1 in A-T patients compared to controls.

Figure 3. STRING diagram of protein-protein interactions and pathway enrichments in CSF of A-T patients. (A) The significant downregulations include pathway enrichments for "Calcium lon Binding" (magenta bullets), "Regulation of Locomotion" (red bullets), "Response To Chemical” (green bullets), "C1q domain" (yellow bullets). (B) The 
significant upregulations include pathway enrichments for "Humoral Immune Response" (forest green bullets), "Complement and Coagulation Cascades" (gold bullets), "Hyaluronan Metabolic Process" (cyan bullets). Previous knowledge of interaction between these factors from experiments, co-expression or text-mining is illustrated by connecting lines of various colors.

Figure 4: In cerebellar tissue from 2-month-old Atm-/- mice (black bars) versus WildType mice (WT, white bars), the mRNA levels were assessed by quantitative real-time reverse-transcriptase PCR for crucial factors in several relevant pathways. (A) Among key factors of apolipoprotein and cholesterol trafficking, significant upregulations were observed for Apoe, Apoh and Cyp46a1. (B) No significant changes were detectable at this stage for any factors in the oxidative stress response. (C) Within the Reelin signaling pathway, the abundance of Reelin mRNA (Reln) was normal, but both Reelin receptors Apoer2 and VIdlr showed significantly reduced transcript levels. (D) Among crucial modulators of the interaction between PN and afferent excitatory presynapses, an elevation was detected for Sema7a, whose gene product is secreted from PN to eliminate climbing fibers. In addition, Vglut2 as a marker of climbing fibers showed a severe reduction. (E) Again, no dysregulation was documented at this stage for markers of DNA damage repair or neuroinflammation. (F) Glutamate receptor exhibited the expected elevation of the NMDA subunit Grin2b levels, which can be triggered by Reelin deficiency, as well as a decrease of Grin2c and increases for the AMPA subunits Gria1 and Gria2, as well as the metabotropic subunit Grm3. (G) Among essential factors of calcium-dependent excitability, the significant downregulations of Atp2b2, Calb1 and Itpr1 clearly reflect incipient dysfunction of Purkinje neurons. (H) Despite various 
changes in PN postsyapses and glutamatergic presynapses, no alterations of the specific cell adhesion factors between cerebellar circuits could be found at this stage.

Figure 5. Schematic overview over apolipoprotein and glutamate signaling modulated via Reelin within neural circuits of the cerebellum (PN for Purkinje neuron, CF for Climbing Fiber, PF for Parallel Fiber, BG for Bergmann Glia, ER for Endoplasmic Reticulum, N for Nucleus). Relevant qPCR findings in the 2-month-old Atm-/- cerebellum were highlighted (red for upregulations, blue for downregulations). 


\section{References}

1. McKinnon PJ (2004) ATM and ataxia telangiectasia. EMBO Rep 5 (8):772-776.

doi:10.1038/sj.embor.7400210

2. Meneret A, Ahmar-Beaugendre Y, Rieunier G, Mahlaoui N, Gaymard B, Apartis E, Tranchant C, RivaudPechoux S, Degos B, Benyahia B, Suarez F, Maisonobe T, Koenig M, Durr A, Stern MH, Dubois d'Enghien C, Fischer A, Vidailhet M, Stoppa-Lyonnet D, Grabli D, Anheim M (2014) The pleiotropic movement disorders phenotype of adult ataxia-telangiectasia. Neurology 83 (12):1087-1095.

doi:10.1212/WNL.0000000000000794

3. Schieving JH, de Vries M, van Vugt JM, Weemaes C, van Deuren M, Nicolai J, Wevers RA, Willemsen MA (2014) Alpha-fetoprotein, a fascinating protein and biomarker in neurology. Eur J Paediatr Neurol 18 (3):243-248. doi:10.1016/j.ejpn.2013.09.003

4. Savitsky K, Bar-Shira A, Gilad S, Rotman G, Ziv Y, Vanagaite L, Tagle DA, Smith S, Uziel T, Sfez S, Ashkenazi M, Pecker I, Frydman M, Harnik R, Patanjali SR, Simmons A, Clines GA, Sartiel A, Gatti RA, Chessa L, Sanal O, Lavin MF, Jaspers NG, Taylor AM, Arlett CF, Miki T, Weissman SM, Lovett M, Collins FS, Shiloh Y (1995) A single ataxia telangiectasia gene with a product similar to PI-3 kinase. Science 268 (5218):1749-1753

5. Herzog KH, Chong MJ, Kapsetaki M, Morgan JI, McKinnon PJ (1998) Requirement for Atm in ionizing radiation-induced cell death in the developing central nervous system. Science 280 (5366):1089-1091 6. Cortez D, Wang Y, Qin J, Elledge SJ (1999) Requirement of ATM-dependent phosphorylation of brca1 in the DNA damage response to double-strand breaks. Science 286 (5442):1162-1166

7. Matsuoka S, Ballif BA, Smogorzewska A, McDonald ER, 3rd, Hurov KE, Luo J, Bakalarski CE, Zhao Z, Solimini N, Lerenthal Y, Shiloh Y, Gygi SP, Elledge SJ (2007) ATM and ATR substrate analysis reveals extensive protein networks responsive to DNA damage. Science 316 (5828):1160-1166.

doi:10.1126/science.1140321

8. Shiloh Y, Ziv Y (2013) The ATM protein kinase: regulating the cellular response to genotoxic stress, and more. Nat Rev Mol Cell Biol 14 (4):197-210

9. Ambrose M, Gatti RA (2013) Pathogenesis of ataxia-telangiectasia: the next generation of ATM functions. Blood 121 (20):4036-4045. doi:10.1182/blood-2012-09-456897

10. Degan P, d'Ischia M, Pallardo FV, Zatterale A, Brusco A, Calzone R, Cavalieri S, Kavakli K, Lloret A, Manini P, Pisanti MA, Vuttariello E, Pagano G (2007) Glutathione levels in blood from ataxia telangiectasia patients suggest in vivo adaptive mechanisms to oxidative stress. Clin Biochem 40 (910):666-670. doi:10.1016/j.clinbiochem.2007.03.013

11. Reichenbach J, Schubert R, Schindler D, Muller K, Bohles H, Zielen S (2002) Elevated oxidative stress in patients with ataxia telangiectasia. Antioxid Redox Signal 4 (3):465-469.

doi:10.1089/15230860260196254

12. Yi M, Rosin MP, Anderson CK (1990) Response of fibroblast cultures from ataxia-telangiectasia patients to oxidative stress. Cancer Lett 54 (1-2):43-50

13. Schubert R, Reichenbach J, Royer N, Pichler M, Zielen S (2000) Spontaneous and oxidative stressinduced programmed cell death in lymphocytes from patients with ataxia telangiectasia (AT). Clin Exp Immunol 119 (1):140-147

14. Ludwig LB, Valiati VH, Palazzo RP, Jardim LB, da Rosa DP, Bona S, Rodrigues G, Marroni NP, Pra D, Maluf SW (2013) Chromosome instability and oxidative stress markers in patients with ataxia telangiectasia and their parents. Biomed Res Int 2013:762048. doi:10.1155/2013/762048 15. Barlow C, Dennery PA, Shigenaga MK, Smith MA, Morrow JD, Roberts LJ, 2nd, Wynshaw-Boris A, Levine RL (1999) Loss of the ataxia-telangiectasia gene product causes oxidative damage in target organs. Proc Natl Acad Sci U S A 96 (17):9915-9919 
16. Chen P, Peng C, Luff J, Spring K, Watters D, Bottle S, Furuya S, Lavin MF (2003) Oxidative stress is responsible for deficient survival and dendritogenesis in purkinje neurons from ataxia-telangiectasia mutated mutant mice. J Neurosci 23 (36):11453-11460

17. Stern N, Hochman A, Zemach N, Weizman N, Hammel I, Shiloh Y, Rotman G, Barzilai A (2002)

Accumulation of DNA damage and reduced levels of nicotine adenine dinucleotide in the brains of Atmdeficient mice. J Biol Chem 277 (1):602-608. doi:10.1074/jbc.M106798200

18. Kamsler A, Daily D, Hochman A, Stern N, Shiloh Y, Rotman G, Barzilai A (2001) Increased oxidative stress in ataxia telangiectasia evidenced by alterations in redox state of brains from Atm-deficient mice. Cancer Res 61 (5):1849-1854

19. Chiesa N, Barlow C, Wynshaw-Boris A, Strata P, Tempia F (2000) Atm-deficient mice Purkinje cells show age-dependent defects in calcium spike bursts and calcium currents. Neuroscience 96 (3):575-583 20. XU Y, Ashley T, Brainerd EE, Bronson RT, Meyn MS, Baltimore D (1996) Targeted disruption of ATM leads to growth retardation, chromosomal fragmentation during meiosis, immune defects, and thymic lymphoma. Genes Dev 10 (19):2411-2422

21. Pietzner J, Baer PC, Duecker RP, Merscher MB, Satzger-Prodinger C, Bechmann I, Wietelmann A, Del Turco D, Doering C, Kuci S, Bader P, Schirmer S, Zielen S, Schubert R (2013) Bone marrow transplantation improves the outcome of Atm-deficient mice through the migration of ATM-competent cells. Hum Mol Genet 22 (3):493-507. doi:10.1093/hmg/dds448

22. Gathmann B, Goldacker S, Klima M, Belohradsky BH, Notheis G, Ehl S, Ritterbusch H, Baumann U, Meyer-Bahlburg A, Witte T, Schmidt R, Borte M, Borte S, Linde R, Schubert R, Bienemann K, Laws HJ, Dueckers G, Roesler J, Rothoeft T, Kruger R, Scharbatke EC, Masjosthusmann K, Wasmuth JC, Moser O, Kaiser P, Gross-Wieltsch U, Classen CF, Horneff G, Reiser V, Binder N, El-Helou SM, Klein C, Grimbacher B, Kindle $G$ (2013) The German national registry for primary immunodeficiencies (PID). Clin Exp Immunol 173 (2):372-380. doi:10.1111/cei.12105

23. Schmitz-Hubsch T, du Montcel ST, Baliko L, Berciano J, Boesch S, Depondt C, Giunti P, Globas C, Infante J, Kang JS, Kremer B, Mariotti C, Melegh B, Pandolfo M, Rakowicz M, Ribai P, Rola R, Schols L, Szymanski S, van de Warrenburg BP, Durr A, Klockgether T, Fancellu R (2006) Scale for the assessment and rating of ataxia: development of a new clinical scale. Neurology 66 (11):1717-1720.

doi:10.1212/01.wnl.0000219042.60538.92

24. Wessel D, Flugge UI (1984) A method for the quantitative recovery of protein in dilute solution in the presence of detergents and lipids. Anal Biochem 138 (1):141-143

25. Cox J, Mann M (2008) MaxQuant enables high peptide identification rates, individualized p.p.b.-range mass accuracies and proteome-wide protein quantification. Nat Biotechnol 26 (12):1367-1372.

doi:10.1038/nbt.1511

26. Cox J, Neuhauser N, Michalski A, Scheltema RA, Olsen JV, Mann M (2011) Andromeda: a peptide search engine integrated into the MaxQuant environment. J Proteome Res 10 (4):1794-1805. doi:10.1021/pr101065j

27. Tyanova S, Temu T, Sinitcyn P, Carlson A, Hein MY, Geiger T, Mann M, Cox J (2016) The Perseus computational platform for comprehensive analysis of (prote)omics data. Nat Methods 13 (9):731-740. doi:10.1038/nmeth.3901

28. Franceschini A, Szklarczyk D, Frankild S, Kuhn M, Simonovic M, Roth A, Lin J, Minguez P, Bork P, von Mering C, Jensen $\sqcup$ (2013) STRING v9.1: protein-protein interaction networks, with increased coverage and integration. Nucleic Acids Res 41 (Database issue):D808-815. doi:10.1093/nar/gks1094

29. Barlow C, Hirotsune S, Paylor R, Liyanage M, Eckhaus M, Collins F, Shiloh Y, Crawley JN, Ried T, Tagle D, Wynshaw-Boris A (1996) Atm-deficient mice: a paradigm of ataxia telangiectasia. Cell 86 (1):159-171 30. Livak KJ, Schmittgen TD (2001) Analysis of relative gene expression data using real-time quantitative PCR and the 2(-Delta Delta C(T)) Method. Methods 25 (4):402-408. doi:10.1006/meth.2001.1262

31. Dzieciatkowska M, Qi G, You J, Bemis KG, Sahm H, Lederman HM, Crawford TO, Gelbert LM, Rothblum-Oviatt C, Wang M (2011) Proteomic Characterization of Cerebrospinal Fluid from Ataxia- 
Telangiectasia (A-T) Patients Using a LC/MS-Based Label-Free Protein Quantification Technology. Int J Proteomics 2011:578903. doi:10.1155/2011/578903

32. Koeppen AH (2005) The pathogenesis of spinocerebellar ataxia. Cerebellum 4 (1):62-73. doi:10.1080/14734220510007950

33. Pesold C, Impagnatiello F, Pisu MG, Uzunov DP, Costa E, Guidotti A, Caruncho HJ (1998) Reelin is preferentially expressed in neurons synthesizing gamma-aminobutyric acid in cortex and hippocampus of adult rats. Proc Natl Acad Sci U S A 95 (6):3221-3226

34. D'Arcangelo G, Miao GG, Chen SC, Soares HD, Morgan JI, Curran T (1995) A protein related to extracellular matrix proteins deleted in the mouse mutant reeler. Nature 374 (6524):719-723. doi:10.1038/374719a0

35. Miyata T, Ono Y, Okamoto M, Masaoka M, Sakakibara A, Kawaguchi A, Hashimoto M, Ogawa M (2010) Migration, early axonogenesis, and Reelin-dependent layer-forming behavior of early/posteriorborn Purkinje cells in the developing mouse lateral cerebellum. Neural Dev 5:23. doi:10.1186/1749-81045-23

36. Hong SE, Shugart YY, Huang DT, Shahwan SA, Grant PE, Hourihane JO, Martin ND, Walsh CA (2000) Autosomal recessive lissencephaly with cerebellar hypoplasia is associated with human RELN mutations. Nat Genet 26 (1):93-96. doi:10.1038/79246

37. Herz J, Chen Y (2006) Reelin, lipoprotein receptors and synaptic plasticity. Nat Rev Neurosci 7 (11):850-859. doi:10.1038/nrn2009

38. Nakamura K, Beppu M, Sakai K, Yagyu H, Matsumaru S, Kohno T, Hattori M (2016) The C-terminal region of Reelin is necessary for proper positioning of a subset of Purkinje cells in the postnatal cerebellum. Neuroscience 336:20-29. doi:10.1016/j.neuroscience.2016.08.039 39. Okoro EU, Zhang H, Guo Z, Yang F, Smith C, Jr., Yang H (2015) A Subregion of Reelin Suppresses Lipoprotein-Induced Cholesterol Accumulation in Macrophages. PLoS One 10 (8):e0136895. doi:10.1371/journal.pone.0136895

40. Sinagra M, Verrier D, Frankova D, Korwek KM, Blahos J, Weeber EJ, Manzoni OJ, Chavis P (2005) Reelin, very-low-density lipoprotein receptor, and apolipoprotein E receptor 2 control somatic NMDA receptor composition during hippocampal maturation in vitro. J Neurosci 25 (26):6127-6136. doi:10.1523/JNEUROSCI.1757-05.2005

41. Darmanto W, Inouye M, Hayasaka S, Takagishi Y, Ogawa M, Mikoshiba K, Murata Y (1998) Disturbed Purkinje cell migration due to reduced expression of Reelin by $X$-irradiation in developing rat cerebellum. Biol Sci Space 12 (3):254-255

42. Lussier AL, Caruncho HJ, Kalynchuk LE (2009) Repeated exposure to corticosterone, but not restraint, decreases the number of reelin-positive cells in the adult rat hippocampus. Neurosci Lett 460 (2):170174. doi:10.1016/j.neulet.2009.05.050

43. Ramos-Moreno T, Galazo MJ, Porrero C, Martinez-Cerdeno V, Clasca F (2006) Extracellular matrix molecules and synaptic plasticity: immunomapping of intracellular and secreted Reelin in the adult rat brain. Eur J Neurosci 23 (2):401-422. doi:10.1111/j.1460-9568.2005.04567.x

44. Niu S, Yabut O, D'Arcangelo G (2008) The Reelin signaling pathway promotes dendritic spine development in hippocampal neurons. J Neurosci 28 (41):10339-10348. doi:10.1523/JNEUROSCI.191708.2008

45. McCullough SD, Xu X, Dent SY, Bekiranov S, Roeder RG, Grant PA (2012) Reelin is a target of polyglutamine expanded ataxin-7 in human spinocerebellar ataxia type 7 (SCA7) astrocytes. Proc Natl Acad Sci U S A 109 (52):21319-21324. doi:10.1073/pnas.1218331110

46. Niu S, Renfro A, Quattrocchi CC, Sheldon M, D'Arcangelo G (2004) Reelin promotes hippocampal dendrite development through the VLDLR/ApoER2-Dab1 pathway. Neuron 41 (1):71-84 47. Zhang G, Assadi AH, McNeil RS, Beffert U, Wynshaw-Boris A, Herz J, Clark GD, D'Arcangelo G (2007) The Pafah1b complex interacts with the reelin receptor VLDLR. PLoS One 2 (2):e252. doi:10.1371/journal.pone.0000252 
48. Assadi AH, Zhang G, Beffert U, McNeil RS, Renfro AL, Niu S, Quattrocchi CC, Antalffy BA, Sheldon M, Armstrong DD, Wynshaw-Boris A, Herz J, D'Arcangelo G, Clark GD (2003) Interaction of reelin signaling and Lis1 in brain development. Nat Genet 35 (3):270-276. doi:10.1038/ng1257

49. Nothwang HG, Kim HG, Aoki J, Geisterfer M, Kubart S, Wegner RD, van Moers A, Ashworth LK, Haaf T, Bell J, Arai H, Tommerup N, Ropers HH, Wirth J (2001) Functional hemizygosity of PAFAH1B3 due to a PAFAH1B3-CLK2 fusion gene in a female with mental retardation, ataxia and atrophy of the brain. Hum Mol Genet $10(8): 797-806$

50. Collette JC, Choubey L, Smith KM (2017) -Glial and stem cell expression of murine Fibroblast Growth Factor Receptor 1 in the embryonic and perinatal nervous system. PeerJ 5:e3519.

doi:10.7717/peerj.3519

51. Rink L, Slupianek A, Stoklosa T, Nieborowska-Skorska M, Urbanska K, Seferynska I, Reiss K, Skorski T (2007) Enhanced phosphorylation of Nbs1, a member of DNA repair/checkpoint complex Mre11-RAD50Nbs1, can be targeted to increase the efficacy of imatinib mesylate against BCR/ABL-positive leukemia cells. Blood 110 (2):651-660. doi:10.1182/blood-2006-08-042630

52. Muller Smith K, Williamson TL, Schwartz ML, Vaccarino FM (2012) Impaired motor coordination and disrupted cerebellar architecture in Fgfr1 and Fgfr2 double knockout mice. Brain Res 1460:12-24. doi:10.1016/j.brainres.2012.04.002

53. Rebustini IT, Hayashi T, Reynolds AD, Dillard ML, Carpenter EM, Hoffman MP (2012) miR-200c regulates FGFR-dependent epithelial proliferation via VIdlr during submandibular gland branching morphogenesis. Development 139 (1):191-202. doi:10.1242/dev.070151

54. Sakamoto I, Ueyama T, Hayashibe M, Nakamura T, Mohri H, Kiyonari H, Shigyo M, Tohda C, Saito N (2018) Roles of Cdc42 and Rac in Bergmann glia during cerebellar corticogenesis. Exp Neurol 302:57-67. doi:10.1016/j.expneurol.2017.12.003

55. Chen X, Guo Z, Okoro EU, Zhang H, Zhou L, Lin X, Rollins AT, Yang H (2012) Up-regulation of ATP binding cassette transporter $\mathrm{A} 1$ expression by very low density lipoprotein receptor and apolipoprotein $\mathrm{E}$ receptor 2. J Biol Chem 287 (6):3751-3759. doi:10.1074/jbc.M111.310888

56. Kobayashi K, Oka K, Forte T, Ishida B, Teng B, Ishimura-Oka K, Nakamuta M, Chan L (1996) Reversal of hypercholesterolemia in low density lipoprotein receptor knockout mice by adenovirus-mediated gene transfer of the very low density lipoprotein receptor. J Biol Chem 271 (12):6852-6860

57. Huang CL, Cheng JC, Kitajima K, Nakano T, Yeh CF, Chong KY, Tseng CP (2010) Disabled-2 is required for mesoderm differentiation of murine embryonic stem cells. J Cell Physiol 225 (1):92-105.

doi:10.1002/jcp.22200

58. Leeb C, Eresheim C, Nimpf J (2014) Clusterin is a ligand for apolipoprotein E receptor 2 (ApoER2) and very low density lipoprotein receptor (VLDLR) and signals via the Reelin-signaling pathway. J Biol Chem 289 (7):4161-4172. doi:10.1074/jbc.M113.529271

59. Konrad L, Hackethal A, Oehmke F, Berkes E, Engel J, Tinneberg HR (2016) Analysis of Clusterin and Clusterin Receptors in the Endometrium and Clusterin Levels in Cervical Mucus of Endometriosis. Reprod Sci 23 (10):1371-1380. doi:10.1177/1933719116641756

60. Andersen OM, Yeung $\mathrm{CH}$, Vorum H, Wellner M, Andreassen TK, Erdmann B, Mueller EC, Herz J, Otto A, Cooper TG, Willnow TE (2003) Essential role of the apolipoprotein E receptor-2 in sperm development. J Biol Chem 278 (26):23989-23995. doi:10.1074/jbc.M302157200

61. Yasuhara O, Aimi Y, Yamada T, Matsuo A, McGeer EG, McGeer PL (1994) Clusterin as a marker for ischaemic Purkinje cells in human brain. Neurodegeneration 3 (4):325-329

62. Norman DJ, Feng L, Cheng SS, Gubbay J, Chan E, Heintz N (1995) The lurcher gene induces apoptotic death in cerebellar Purkinje cells. Development 121 (4):1183-1193

63. Russell MB (2010) Genetics of dementia. Acta Neurol Scand Suppl (190):58-61. doi:10.1111/j.16000404.2010.01377.x

64. Thambisetty M, An Y, Kinsey A, Koka D, Saleem M, Guntert A, Kraut M, Ferrucci L, Davatzikos C, Lovestone S, Resnick SM (2012) Plasma clusterin concentration is associated with longitudinal brain 
atrophy in mild cognitive impairment. Neuroimage 59 (1):212-217.

doi:10.1016/j.neuroimage.2011.07.056

65. Niessen HW, Lagrand WK, Rensink HJ, Meijer CJ, Aarden L, Hack CE, Visser C (2000) Apolipoprotein H, a new mediator in the inflammatory changes ensuring in jeopardised human myocardium. J Clin Pathol $53(11): 863-867$

66. Wang Y, Guo Y, Wang X, Huang J, Shang J, Sun S (2011) Human serum amyloid P functions as a negative regulator of the innate and adaptive immune responses to DNA vaccines. J Immunol 186 (5):2860-2870. doi:10.4049/jimmunol.1003641

67. Zheng L, Wu T, Zeng C, Li X, Wen D, Ji T, Lan T, Xing L, Li J, He X, Wang L (2016) SAP deficiency mitigated atherosclerotic lesions in ApoE(-/-) mice. Atherosclerosis 244:179-187.

doi:10.1016/j.atherosclerosis.2015.11.009

68. Borovkova El, Antipova NV, Komeenko TV, Shakhparonov MI, Borovkov IM (2017) Paraoxonase: The Universal Factor of Antioxidant Defense in Human Body. Vestn Ross Akad Med Nauk 72 (1):5-10. doi:10.15690/vramn764

69. Chistiakov DA, Melnichenko AA, Orekhov AN, Bobryshev YV (2017) Paraoxonase and atherosclerosisrelated cardiovascular diseases. Biochimie 132:19-27. doi:10.1016/j.biochi.2016.10.010

70. Deakin S, Moren X, James RW (2005) Very low density lipoproteins provide a vector for secretion of paraoxonase-1 from cells. Atherosclerosis 179 (1):17-25. doi:10.1016/j.atherosclerosis.2004.08.039

71. Rosenblat M, Ward S, Volkova N, Hayek T, Aviram M (2012) VLDL triglycerides inhibit HDL-associated paraoxonase 1 (PON1) activity: in vitro and in vivo studies. Biofactors 38 (4):292-299.

doi:10.1002/biof.1021

72. van Himbergen TM, van Tits L, Ter Avest E, Roest M, Voorbij HA, de Graaf J, Stalenhoef AF (2008) Paraoxonase (PON1) is associated with familial combined hyperlipidemia. Atherosclerosis 199 (1):87-94. doi:10.1016/j.atherosclerosis.2007.10.017

73. Chetty C, Dontula R, Gujrati M, Dinh DH, Lakka SS (2012) Blockade of SOX4 mediated DNA repair by SPARC enhances radioresponse in medulloblastoma. Cancer Lett 323 (2):188-198.

doi:10.1016/j.canlet.2012.04.014

74. Wang W, Karagogeos D, Kilpatrick DL (2011) The effects of Tag-1 on the maturation of mouse cerebellar granule neurons. Cell Mol Neurobiol 31 (3):351-356. doi:10.1007/s10571-010-9641-6

75. Kyriakopoulou K, de Diego I, Wassef M, Karagogeos D (2002) A combination of chain and neurophilic migration involving the adhesion molecule TAG-1 in the caudal medulla. Development 129 (2):287-296 76. Saha B, Ypsilanti AR, Boutin C, Cremer H, Chedotal A (2012) Plexin-B2 regulates the proliferation and migration of neuroblasts in the postnatal and adult subventricular zone. J Neurosci 32 (47):16892-16905. doi:10.1523/JNEUROSCI.0344-12.2012

77. Vaillant C, Michos O, Orolicki S, Brellier F, Taieb S, Moreno E, Te H, Zeller R, Monard D (2007) Protease nexin 1 and its receptor LRP modulate SHH signalling during cerebellar development.

Development 134 (9):1745-1754. doi:10.1242/dev.02840

78. Nakayama M, Nakajima D, Yoshimura R, Endo Y, Ohara O (2002) MEGF1/fat2 proteins containing extraordinarily large extracellular domains are localized to thin parallel fibers of cerebellar granule cells. Mol Cell Neurosci 20 (4):563-578

79. Nibbeling EAR, Duarri A, Verschuuren-Bemelmans CC, Fokkens MR, Karjalainen JM, Smeets $C$, de Boer-Bergsma JJ, van der Vries G, Dooijes D, Bampi GB, van Diemen C, Brunt E, Ippel E, Kremer B, Vlak M, Adir N, Wijmenga C, van de Warrenburg BPC, Franke L, Sinke RJ, Verbeek DS (2017) Exome sequencing and network analysis identifies shared mechanisms underlying spinocerebellar ataxia. Brain 140 (11):2860-2878. doi:10.1093/brain/awx251

80. Squarr AJ, Brinkmann K, Chen B, Steinbacher T, Ebnet K, Rosen MK, Bogdan S (2016) Correction: Fat2 acts through the WAVE regulatory complex to drive collective cell migration during tissue rotation. J Cell Biol 212 (7):883. doi:10.1083/jcb.20150808103082016c 
81. Miura E, Matsuda K, Morgan Jl, Yuzaki M, Watanabe M (2009) Cbln1 accumulates and colocalizes with Cbln3 and GluRdelta2 at parallel fiber-Purkinje cell synapses in the mouse cerebellum. Eur J Neurosci 29 (4):693-706. doi:10.1111/j.1460-9568.2009.06632.x 82. Takeuchi E, Ito-Ishida A, Yuzaki M, Yanagihara D (2018) Improvement of cerebellar ataxic gait by injecting Cbln1 into the cerebellum of cbln1-null mice. Sci Rep 8 (1):6184. doi:10.1038/s41598-01824490-0

83. Sioletic S, Czaplinski J, Hu L, Fletcher JA, Fletcher CD, Wagner AJ, Loda M, Demetri GD, Sicinska ET, Snyder EL (2014) c-Jun promotes cell migration and drives expression of the motility factor ENPP2 in soft tissue sarcomas. J Pathol 234 (2):190-202. doi:10.1002/path.4379

84. Uesaka N, Uchigashima M, Mikuni T, Nakazawa T, Nakao H, Hirai H, Aiba A, Watanabe M, Kano M (2014) Retrograde semaphorin signaling regulates synapse elimination in the developing mouse brain. Science 344 (6187):1020-1023. doi:10.1126/science.1252514

85. Lee S, Takeda Y, Kawano H, Hosoya H, Nomoto M, Fujimoto D, Takahashi N, Watanabe K (2000)

Expression and regulation of a gene encoding neural recognition molecule NB-3 of the contactin/F3 subgroup in mouse brain. Gene 245 (2):253-266

86. Cui XY, Hu QD, Tekaya M, Shimoda Y, Ang BT, Nie DY, Sun L, Hu WP, Karsak M, Duka T, Takeda Y, Ou LY, Dawe GS, Yu FG, Ahmed S, Jin LH, Schachner M, Watanabe K, Arsenijevic Y, Xiao ZC (2004) NB3/Notch1 pathway via Deltex1 promotes neural progenitor cell differentiation into oligodendrocytes. J Biol Chem 279 (24):25858-25865. doi:10.1074/jbc.M313505200

87. Takeda Y, Akasaka K, Lee S, Kobayashi S, Kawano H, Murayama S, Takahashi N, Hashimoto K, Kano M, Asano M, Sudo K, Iwakura Y, Watanabe K (2003) Impaired motor coordination in mice lacking neural recognition molecule NB-3 of the contactin/F3 subgroup. J Neurobiol 56 (3):252-265.

doi:10.1002/neu.10222

88. Hinsinger G, Galeotti N, Nabholz N, Urbach S, Rigau V, Demattei C, Lehmann S, Camu W, Labauge P, Castelnovo G, Brassat D, Loussouarn D, Salou M, Laplaud D, Casez O, Bockaert J, Marin P, Thouvenot E (2015) Chitinase 3-like proteins as diagnostic and prognostic biomarkers of multiple sclerosis. Mult Scler 21 (10):1251-1261. doi:10.1177/1352458514561906

89. Sanfilippo C, Longo A, Lazzara F, Cambria D, Distefano G, Palumbo M, Cantarella A, Malaguarnera L, Di Rosa M (2017) CHI3L1 and CHI3L2 overexpression in motor cortex and spinal cord of sALS patients. Mol Cell Neurosci 85:162-169. doi:10.1016/j.mcn.2017.10.001

90. Matthews KW, Mueller-Ortiz SL, Wetsel RA (2004) Carboxypeptidase N: a pleiotropic regulator of inflammation. Mol Immunol 40 (11):785-793

91. Kurokawa J, Arai S, Nakashima K, Nagano H, Nishijima A, Miyata K, Ose R, Mori M, Kubota N, Kadowaki T, Oike Y, Koga H, Febbraio M, Iwanaga T, Miyazaki T (2010) Macrophage-derived AIM is endocytosed into adipocytes and decreases lipid droplets via inhibition of fatty acid synthase activity. Cell Metab 11 (6):479-492. doi:10.1016/j.cmet.2010.04.013

92. Miyazaki T, Kurokawa J, Arai S (2011) AIMing at metabolic syndrome. -Towards the development of novel therapies for metabolic diseases via apoptosis inhibitor of macrophage (AIM). Circ J 75 (11):25222531

93. Sanjurjo L, Aran G, Roher N, Valledor AF, Sarrias MR (2015) AIM/CD5L: a key protein in the control of immune homeostasis and inflammatory disease. J Leukoc Biol 98 (2):173-184. doi:10.1189/jlb.3RU0215074R

94. Wang C, Yosef N, Gaublomme J, Wu C, Lee Y, Clish CB, Kaminski J, Xiao S, Meyer Zu Horste G, Pawlak M, Kishi Y, Joller N, Karwacz K, Zhu C, Ordovas-Montanes M, Madi A, Wortman I, Miyazaki T, Sobel RA, Park H, Regev A, Kuchroo VK (2015) CD5L/AIM Regulates Lipid Biosynthesis and Restrains Th17 Cell Pathogenicity. Cell 163 (6):1413-1427. doi:10.1016/j.cell.2015.10.068

95. Schreck SF, Parker C, Plumb ME, Sodetz JM (2000) Human complement protein C8 gamma. Biochim Biophys Acta 1482 (1-2):199-208 
96. Spath GF, Ramadori G, Rittner C, Schneider PM (1995) Expression of the complement C8 genes during interleukin-6-mediated in vitro induction of the acute-phase response. Exp Clin Immunogenet 12 (1):53-

60

97. Trouw LA, Nilsson SC, Goncalves I, Landberg G, Blom AM (2005) C4b-binding protein binds to necrotic cells and DNA, limiting DNA release and inhibiting complement activation. J Exp Med 201 (12):19371948. doi:10.1084/jem.20050189

98. Pineiro M, Alava MA, Gonzalez-Ramon N, Osada J, Lasierra P, Larrad L, Pineiro A, Lampreave F (1999) ITIH4 serum concentration increases during acute-phase processes in human patients and is upregulated by interleukin- 6 in hepatocarcinoma HepG2 cells. Biochem Biophys Res Commun 263 (1):224229. doi:10.1006/bbrc.1999.1349

99. Pineiro M, Andres M, Iturralde M, Carmona S, Hirvonen J, Pyorala S, Heegaard PM, Tjornehoj K, Lampreave F, Pineiro A, Alava MA (2004) ITIH4 (inter-alpha-trypsin inhibitor heavy chain 4) is a new acute-phase protein isolated from cattle during experimental infection. Infect Immun 72 (7):3777-3782. doi:10.1128/IAI.72.7.3777-3782.2004

100. Barnes JA, Ebner BA, Duvick LA, Gao W, Chen G, Orr HT, Ebner TJ (2011) Abnormalities in the climbing fiber-Purkinje cell circuitry contribute to neuronal dysfunction in ATXN1[82Q] mice. J Neurosci 31 (36):12778-12789. doi:10.1523/JNEUROSCI.2579-11.2011

101. Groc L, Choquet D, Stephenson FA, Verrier D, Manzoni OJ, Chavis P (2007) NMDA receptor surface trafficking and synaptic subunit composition are developmentally regulated by the extracellular matrix protein Reelin. J Neurosci 27 (38):10165-10175. doi:10.1523/JNEUROSCI.1772-07.2007

102. Cheng A, Zhao T, Tse KH, Chow HM, Cui Y, Jiang L, Du S, Loy MMT, Herrup K (2018) ATM and ATR play complementary roles in the behavior of excitatory and inhibitory vesicle populations. Proc Natl Acad Sci U S A 115 (2):E292-E301. doi:10.1073/pnas.1716892115

103. Beffert U, Weeber EJ, Durudas A, Qiu S, Masiulis I, Sweatt JD, Li WP, Adelmann G, Frotscher M, Hammer RE, Herz J (2005) Modulation of synaptic plasticity and memory by Reelin involves differential splicing of the lipoprotein receptor Apoer2. Neuron 47 (4):567-579. doi:10.1016/j.neuron.2005.07.007 104. Slemmer JE, De Zeeuw Cl, Weber JT (2005) Don't get too excited: mechanisms of glutamatemediated Purkinje cell death. Prog Brain Res 148:367-390. doi:10.1016/S0079-6123(04)48029-7 105. Hellwig S, Hack I, Kowalski J, Brunne B, Jarowyj J, Unger A, Bock HH, Junghans D, Frotscher M (2011) Role for Reelin in neurotransmitter release. J Neurosci 31 (7):2352-2360. doi:10.1523/JNEUROSCI.398410.2011

106. Fatemi SH, Reutiman TJ, Folsom TD (2009) Chronic psychotropic drug treatment causes differential expression of Reelin signaling system in frontal cortex of rats. Schizophr Res 111 (1-3):138-152. doi:10.1016/j.schres.2009.03.002 
A
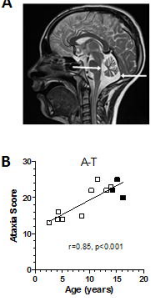
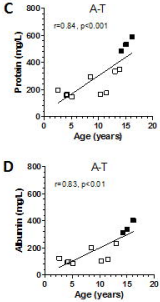
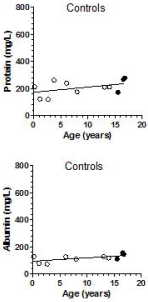
A

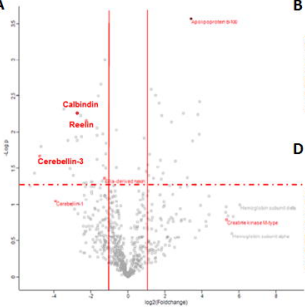

B

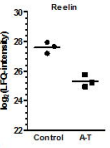

C

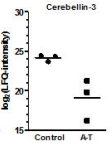

E
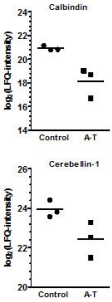


\section{A}

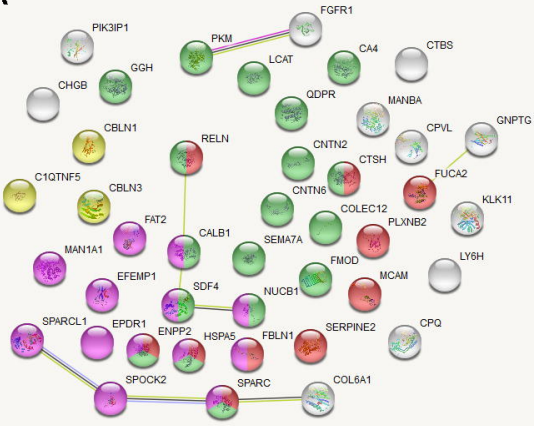

B

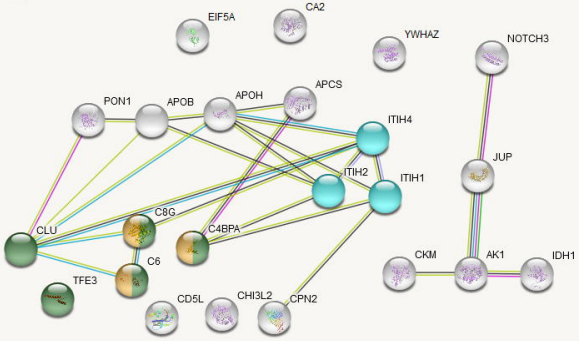


N

\section{Reelin}

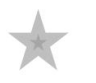

ApoD ApoJ

ApoB

$\searrow$

$$
\text { ApoE }
$$

ApoH

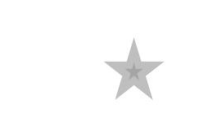

O

\section{$\star$}

$\downarrow$ Reelin

GRIN1 GRIN2A GRIN2B GRIA1 GRIA2 GRIN2C GRIN2D GRIA3 GRIA4 GRIN3A GRIN3B

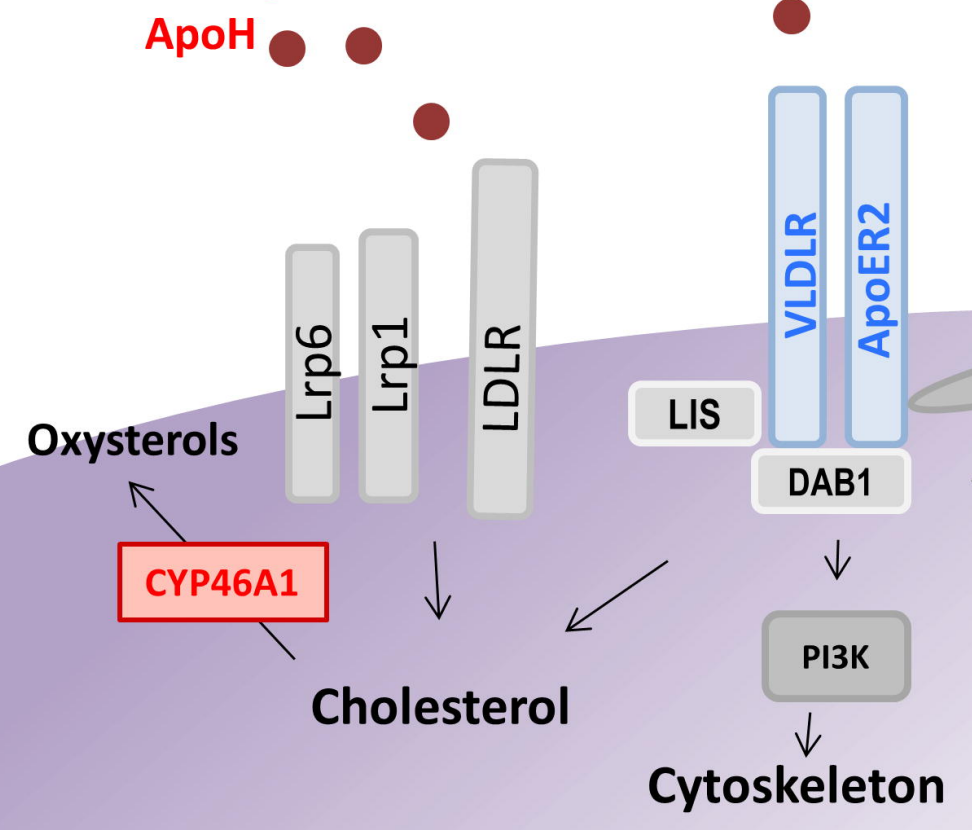

NMDAR

\section{AMPAR}
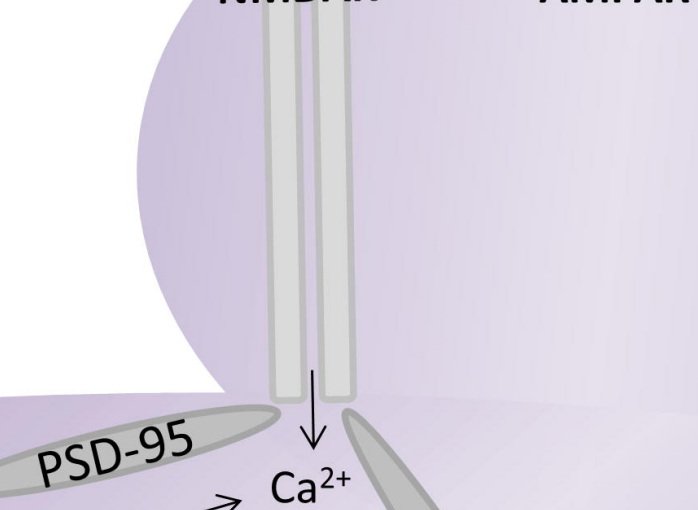